\title{
Corrigendum: ncRNAs: New Players in Mitochondrial Health and Disease?
}

\section{OPEN ACCESS}

Approved by:

Frontiers Editorial Office,

Frontiers Media SA, Switzerland

*Correspondence: Holger Prokisch

prokisch@helmholtz-muenchen.de

Specialty section This article was submitted to Epigenomics and Epigenetics, a section of the journal

Frontiers in Genetics

Received: 06 March 2020 Accepted: 09 March 2020

Published: 20 March 2020

Citation:

Gusic $M$ and Prokisch H (2020) Corrigendum: ncRNAs: New Players in Mitochondrial Health and Disease?

Front. Genet. 11:288

doi: 10.3389/fgene.2020.00288

\author{
Mirjana Gusic ${ }^{1,2,3}$ and Holger Prokisch ${ }^{1,3 *}$ \\ ${ }^{1}$ Institute of Human Genetics, Helmholtz Zentrum München, Neuherberg, Germany, ${ }^{2}$ DZHK (German Centre for \\ Cardiovascular Research), partner site Munich Heart Alliance, Munich, Germany, ${ }^{3}$ Institute of Human Genetics, Technical \\ University of Munich, Munich, Germany
}

Keywords: mitochondria, ncRNA, IncRNA, miRNA, mtDNA, micropeptide

\section{A Corrigendum on}

ncRNAs: New Players in Mitochondrial Health and Disease?

by Gusic, M., and Prokisch, H. (2020). Front. Genet. 11:95. doi: 10.3389/fgene.2020.00095

In the original article, there were mistakes in Figure $\mathbf{5}$ and Figure $\mathbf{6}$ as published. Figures are stating miR-167b instead of the correct miR-147b. The corrected Figure 5 and Figure 6 appear below.

The authors apologize for this error and state that this does not change the scientific conclusions of the article in any way. The original article has been updated.

Copyright () 2020 Gusic and Prokisch. This is an open-access article distributed under the terms of the Creative Commons Attribution License (CC BY). The use, distribution or reproduction in other forums is permitted, provided the original author(s) and the copyright owner(s) are credited and that the original publication in this journal is cited, in accordance with accepted academic practice. No use, distribution or reproduction is permitted which does not comply with these terms. 


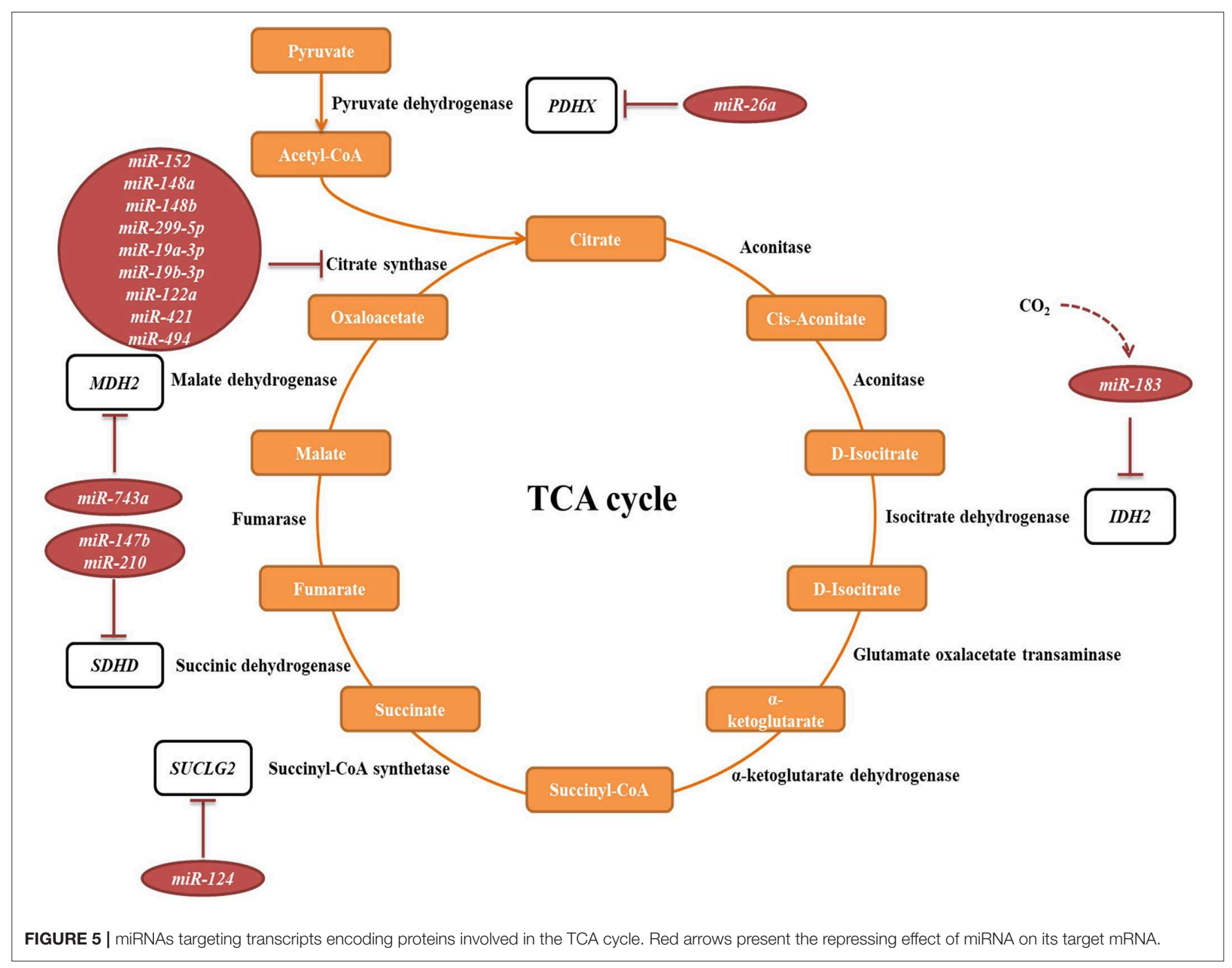




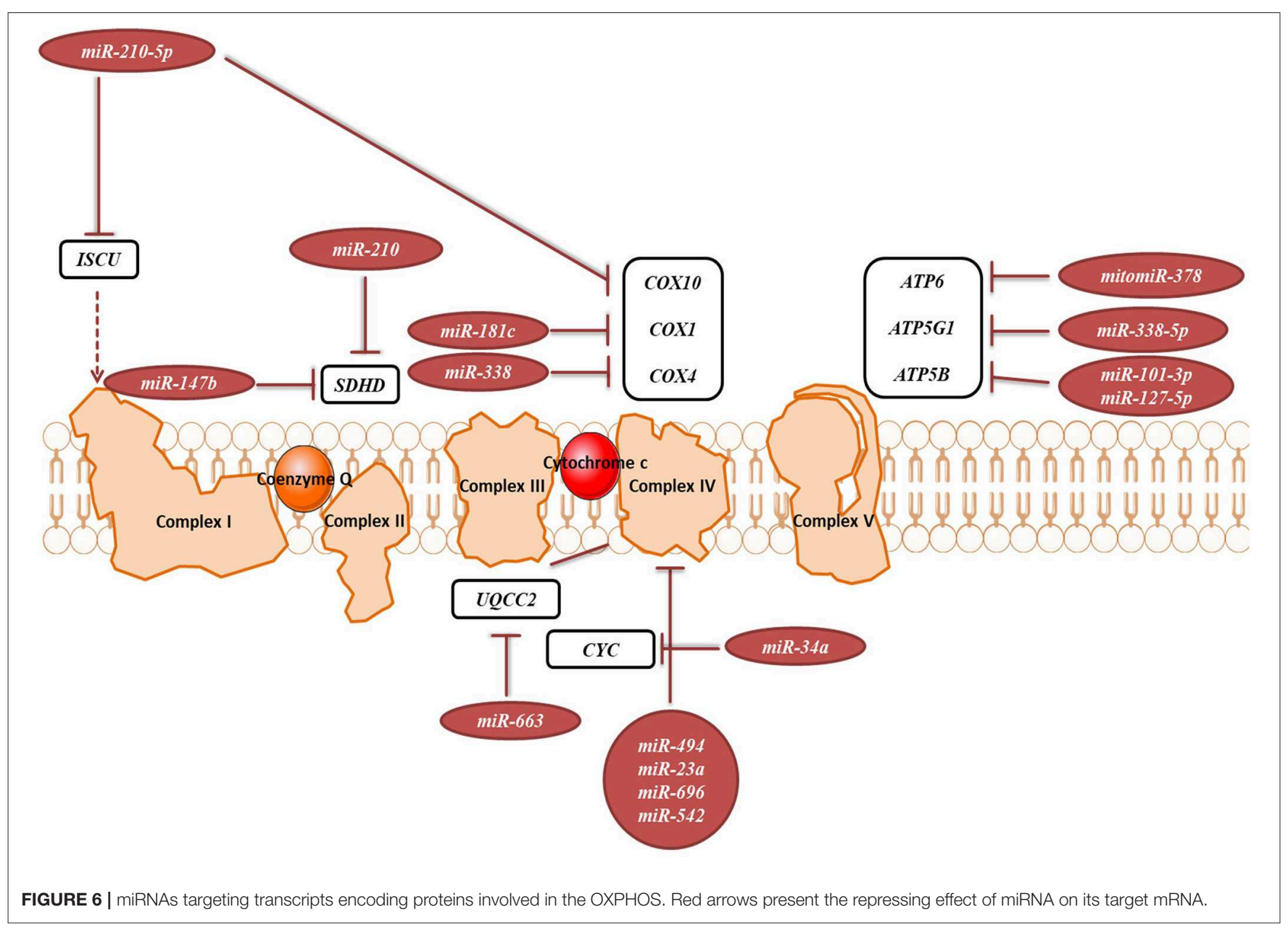

